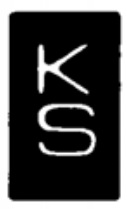



Tim Epkenhans .

Moral und Disziplin 
ISLAMKUNDLICHE UNTERSUCHUNGEN • BAND 264

\author{
begründet \\ von \\ Klaus Schwarz \\ herausgegeben \\ von \\ Gerd Winkelhane
}


ISLAMKUNDLICHE UNTERSUCHUNGEN • BAND 264

\section{Tim Epkenhans}

\section{Moral und Disziplin}

Seyyed Ḥasan Taqizāde und die Konstruktion eines „progressiven Selbst“ in der frühen iranischen Moderne 
Bibliografische Information Der Deutschen Bibliothek

Die Deutsche Bibliothek verzeichnet diese Publikation in der Deutschen Nationalbibliografie; detaillierte bibliografische Daten sind im Internet über http://dnb.ddb.de abrufbar.

Alle Rechte vorbehalten.

Ohne ausdrückliche Genehmigung des Verlages

ist es nicht gestattet, das Werk oder einzelne Teile daraus

nachzudrucken oder zu vervielfältigen.

c) Gerd Winkelhane, Berlin 2005.

Klaus Schwarz Verlag GmbH, Postfach 4102 40, D-12112 Berlin

ISBN 3-87997-322-9

Druck: Offsetdruckerei Gerhard Weinert GmbH, D-12099 Berlin

ISSN 0939-1940

ISBN 3-87997-322-9 